\title{
VV-TOMM: capacity building in remote tourism territories through the first European transnational application of the Tourism Optimization Management Model
}

\author{
A. Jiricka, B. Salak, A. Arnberger, R. Eder \& U. Pröbstl-Haider \\ University of Natural Resources and Life Sciences, Austria
}

\begin{abstract}
Management concepts for sustainable tourism development tackle the challenges of preventing the use of natural, socio-cultural and economic resources from turning into the abuse of such resources. Their major aim is keeping the balance between visitor numbers and the welfare of the local environment and population. In 1997, a new approach was elaborated - the Tourism Optimization Management Model, called TOMM for short. In contrast to other management approaches, TOMM acts as a motivator to achieve results which will be appreciated by all tourism actors. Rather than focusing on limits, it strives towards a process of mobilisation and identity building. Within a three-year transnational research project - focused on remote areas under transition to a strategic development of tourism - TOMM was first applied in a transnational European context. This paper analyses the potential and flexibility of the TOMM framework under special preconditions: all study areas were either just beginning tourism activities or were re-establishing their tourism businesses. The transnational application in this paper examines the ability of the TOMM-process to introduce a 'strategic' sustainable tourism management concept under difficult conditions, such as low tourism budgets, missing tourism data, heterogeneous stakeholder structures or lack of commitment by stakeholders. Findings of this international comparison demonstrate the potential of the TOMM-framework to encourage a learning process about successful and sustainable destination development, and about the need to monitor multidimensional data in order to survey and adapt the tourism strategy if needed.
\end{abstract}

Keywords: tourism monitoring, destination management, stakeholder involvement. 


\section{Introduction}

Keeping the balance between the multiple influences of visitors and the welfare of the local environment and population is the major aim of numerous tourism management concepts elaborated over the last thirty years. In order to define an approach which is based more on motivation and common values rather than on thresholds and limits, a new approach was elaborated - the Tourism Optimization Management Model (called TOMM for short). "The vision of TOMM is to be a centre of excellence and inspirational leader in destination management" [2]. Methodological comparisons classify TOMM as the most collaborative and transparent framework, compared to other visitor management concepts [3].

Within a transnational research project, called Vital Villages (VV), the successful application of the Australian framework was tested for different sites with various conditions. The developed TOMM-adaptation was named the VV-TOMM model after the project acronym. In contrast to the Australian situation, VV-TOMM was developed for remote destinations with unexploited tourism potential in the European context. Such remote areas, with little or no tourism development and a strong need for a strategic development concept, are a useful testing ground for sustainable tourism development.

This paper analyses the potential and flexibility of the TOMM framework under specific conditions:

1. Remote areas just beginning tourism activities or re-establishing their tourism business

2. Lack of management structures in several case study areas, determined by an analysis of governance structures (prior to the TOMM application)

3. Partial or near complete lack of monitoring systems, data availability and indicator usage, due to low awareness of the need to elaborate such systems

The transnational application in this paper examines the ability of the TOMM-process to:

- introduce a strategic tourism management system under difficult conditions, such as low tourism budgets, heterogeneous stakeholder structures, lack of commitment by stakeholders etc.,

- start an awareness-raising process for coordinated and structured development,

- encourage stakeholder interaction,

- learn from the process itself about successful destination development and the positioning of new attractions.

\section{Background}

\subsection{Sustainable tourism through visitor management concepts}

Management concepts for sustainable tourism development tackle the challenges of preventing use of natural, socio-cultural and economic resources from turning into abuse of the same. Their major aim is keeping the balance between visitor 
numbers and the welfare of the local environment and population. For the last 30 years, several frameworks have been developed by different organisations, mostly US or Canadian Park or Forest Services, and have been tested in their respective settings. These frameworks partly rely on the concept of carrying capacity. Examples of such visitor management concepts are the Recreation Opportunity Spectrum (ROS), Visitor Impact Management (VIM), Limits of Acceptable Change (LAC), and the Visitor Experience and Resource Protection (VERP) [4-7]. In Canada, the Visitor Activity Management Process (VAMP) was developed for the Canadian Park Service, but Canada also applies ROS and LAC processes. Most of these frameworks were developed more than 30 years ago. While these frameworks are very common in the US, few applications exist in Europe [8] and Asia.

Several of the frameworks mentioned above primarily aim at identifying goals and limits. The framework of the Tourism Optimization Management Model (TOMM) originated in Australia and followed a different approach [1, 3]. In contrast to other approaches, TOMM acts as a motivator to achieve results which will be appreciated by all tourism actors [9]. Rather than focusing on limits, it strives towards a process of mobilisation and identity building.

TOMM was developed for a "tourism icon destination" where the local people realised the necessity to preserve their natural resources to maintain the attractiveness of their destination. "The people of Kangaroo Island see prosperity in tourism, but they know that what they have is a unique resource that must be managed carefully if it is not to be destroyed. They are working hard to find the delicate balance between development and conservation" [2]. The idea was to build on these common values and to formulate together the desired tourismrelated conditions along which all future processes would be oriented.

Ideally, increased tourism activities should be based on detailed information about their impacts. As a consequence, the idea of a management and response system was born. The process was fundamentally led by key government agencies and community groups "to develop a unified strategic direction to address the changes being ushered in by tourism" [2].

TOMM is a framework that involves a learning process for all stakeholders involved. Based on a continuous stream of information, the idea was to create awareness through an increase of knowledge about coherences between tourism activities and their impact on several different dimensions. It inspires people to contribute to a common achievement of visions. Following this approach, TOMM tries to minimise conflicts by creating mutually shared desired conditions [10]. TOMM is further characterised by a strong orientation towards future benefits and emerging issues [11]. Its main intentions are not only to monitor tourism activities but also to facilitate the decision making process, in order to make better, more sustainable decisions [12].

TOMM integrates more aspects than just the environmental and market components [9]. Thereby, it acknowledges the dependence of the tourism industry on the quality of the visitor experience and the condition of the natural, cultural and social resources, and emphasises this during the long-term monitoring process [1]. 


\subsection{The TOMM-process}

TOMM follows a three-step approach, described in the following studies $[1,2,13]$.

In phase one, the destination gains a deeper understanding of the options and alternatives related to tourism development. The individual stakeholders have a commonly based understanding of the desired future development. This shared awareness of their own resources, and the visualisation of visions and strengths, is a fundamental and essential factor for successful results.

The second phase refines the output of phase one. The vision is broken down into desired conditions, which address the diverse components of a tourism product:

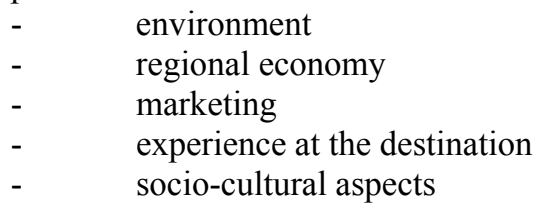

To identify and measure achievements regarding the desired conditions, indicators are selected. Indicators are defined according to the needs and special requirements of the destination [14]. These indicators are adapted by collaborative planning and broad stakeholder involvement. Afterwards, "acceptable ranges" are determined, based on participatory agreement. These ranges guide the destination on its way to achieving optimal desired conditions a steady improvement provided. Consequently, the destination stakeholders survey 'the performance of each indicator and identify any need for action.

These ranges can be adapted after each monitoring period, which is part of the third phase. In case the acceptable ranges of the indicators cannot be reached, which is revealed in a monitoring and response phase, management response options have to be found. The identification of cause-effect relationships is essential.

As the main output of phase three, destinations can compare their 'performance' with benchmarks identified in phase one and the ranges set in the implementation phase. As a result of the information gained, it is then determined whether and in which category adaptation or modification is required, and which management actions need to be defined, have proven to be successful, or need amendment.

\section{Design for VV-TOMM}

The European application of TOMM was part of a transnational research project with eight case study areas in seven countries, including Austria, Germany, Italy, Czech Republic, Slovenia and Poland. Within the scope of the Interreg Central Europe project "Listen to the voice of villages", sustainable tourism development was the major goal. The emphasis was set on niche tourism products suited to the cultural background and natural highlights of the case study areas [15]. 
The following criteria were used for the selection of the case study areas:

- Remoteness of the area

- Start-up of tourism initiatives or re-establishing of tourism development

- Low level of organisational structure of tourism management in the destination compared to other 'established' destinations

As all study areas were either just beginning or re-establishing their tourism business, it was possible to implement an approach towards sustainable development in all case studies. The LISTEN areas were far from reaching limits and in many cases possess precious cultural heritage or natural assets, or both. In some of the pilot areas, traditional housing as well as ancient language and customs - hence the socio-cultural values - are a major topic, whereas others profit primarily from valuable cultural landscapes and/or protected areas.

Within the research project the authors were, on the one hand, involved in the process as experts together with the University of Trento Economic department. In addition to this, the University of Natural Resources and Life Sciences Vienna (BOKU) was also responsible for the implementation process of TOMM in an Austrian case study area in southern Burgenland.

The following table (Table 1) presents relevant elements of the TOMM process which are subject to the analysis.

Table 1: Elements of the TOMM process subject to this study.

\begin{tabular}{|l|l|}
\hline TOMM-levels & Relevant aspects \\
\hline $\begin{array}{l}\text { Identification of desired } \\
\text { conditions and common } \\
\text { values }\end{array}$ & $\begin{array}{l}\text { Destination perspectives, recognition of the } \\
\text { added value of sustainable development, } \\
\text { collaboration of tourism players and resources }\end{array}$ \\
\hline Indicator compilation & $\begin{array}{l}\text { Following long-term needs/perspectives, based } \\
\text { on common agreement, selected by all } \\
\text { stakeholders }\end{array}$ \\
\hline $\begin{array}{l}\text { Data-collection for } \\
\text { monitoring }\end{array}$ & $\begin{array}{l}\text { Linkage to existing data-systems, resources for } \\
\text { regular updates, personnel and financial effort }\end{array}$ \\
\hline Continuation of VV-TOMM after the international project-lifetime \\
\hline $\begin{array}{l}\text { Interest for long-term } \\
\text { monitoring system, } \\
\begin{array}{l}\text { Adoption of management } \\
\text { measures }\end{array}\end{array}$ & $\begin{array}{l}\text { Set-up of a strategic tourism management } \\
\text { structure, valid after the project lifetime; } \\
\text { formulation of reactive management measures } \\
\text { according to monitoring results }\end{array}$ \\
\hline
\end{tabular}

The application of TOMM in this specific context was conceptualised to answer the following research questions and hypotheses:

- TOMM encourages awareness in a destination for strategic tourism development at different levels of tourism management, and initiates a learning process, 
- TOMM is explicitly suitable for areas with beginning or re-establishing tourism development, since it provides orientation, transparency and opportunities for collaboration. It does not address limits, which tourism stakeholders often perceive as discouraging,

- External knowledge is needed to elaborate TOMM, in particular in areas with beginning or re-establishing tourism initiatives.

Our transnational case study approach allowed the influence of TOMM on a collective learning process to be reflected at two levels:

1. on the transnational project level - which mainly addressed the responsible partners of the project in the eight participating countries. They were composed of representatives of regional development organisations as well as of DMOs,

2. on the regional application level - which comprises a larger group of stakeholders. In this context the before mentioned group (under 1) had a crucial role in knowledge transfer.

\section{Results}

\subsection{Formulation of relevant desired conditions and selection of indicators}

According to the original KI-TOMM framework [1], the major topics were elaborated under the five categories environment, socio-cultural aspects, marketing, visitor experience and regional economy. The identification of desired conditions was derived in a participatory manner from an analysis of the pilot areas and their development aims and needs.

Given the heterogeneous planning /starting conditions at the different case study areas, support was needed to identify the main topics relevant for remote areas under transition to sustainable tourism development. The BOKU University introduced TOMM and provided expert advice for the identification of core tourism management topics and the identification of desired conditions for the study areas. As the project partners in the pilot areas had different professional backgrounds (economic, ecological or planning), it was difficult for them to identify suitable indicators for all categories by themselves. With the support of the 'expert steering committee', however, they had a sound base for selecting their topics and amplifying or modifying the desired conditions and indicators to their needs.

The expert committee provided the LISTEN partner areas with a VV-indicator table, which included options for relevant desired conditions, a set of indicators specific to the desired conditions and a specification of information required to measure these indicators based on international studies and guidelines $[9,16,17]$. The chart of possible indicators, provided as an example, gave the regions the opportunity to consider data and indicators they already compiled or had in use. At this step, all of the regions' stakeholders were involved. After initial feedback on the indicators chosen in the regions by the local and regional stakeholders, a meeting took place to discuss the selection results. The expert team gave recommendations on which additional indicators 
could also be relevant. The results of the second indicator selection phase, in comparison to the first phase before the feedback round, are presented in Figure 1 .

This figure shows the benefits of expert induced feedback loops in a cooperative planning design. Before the feedback rounds, the future benefits of an indicator-based evaluation of tourism performance were critically discussed among the partners. They argued that data collection would be too difficult for at least several indicators. Thus, the number of sustainability indicators they had selected was partially quite low. Particularly the environmental indicators were scarcely chosen. Similarities to the original application can be observed, where environmental indicators were considered to be rather weak [11]. This could be a result of the holistic focus on five dimensions, compared to other frameworks that focus more exclusively on ecological impacts. Information on 'creative data compilation', easy access to data and involvement of potentially relevant stakeholders was added by the experts, which lead to a re-consideration of the initial selection.

The second phase of indicator selection reflects the regions' understanding of a need to apply sustainability indicators, especially for long-term monitoring. The question and answer forum - a place where all project partners could ask general and specific questions concerning the implementation phase of VV-TOMM and their specific pilot projects - tried to clarify uncertainties, but also revealed the necessity to apply the indicators regularly and to monitor their performance. Consequently, both efforts (costs) and benefits were evident. These changes in the partners' perception of the VV-TOMM model are reflected in a more diverse indicator selection, with a better balance between the categories in the second phase.

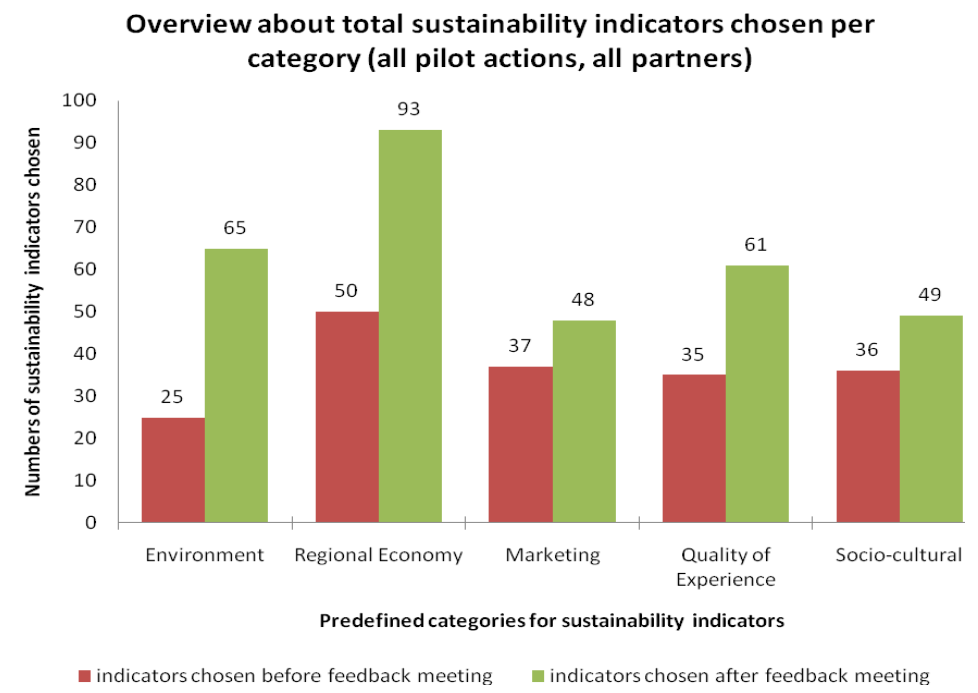

Figure 1: Overview of the indicator selection process. 
The average number of indicators chosen per case study (in context to a new orientation of their tourism strategy through a project "pilot action") area was 23 (out of 50 indicators elaborated by the experts, together with the stakeholders represented in the project, as a basis for selection). Half of the pilot partners selected a rather broad spectrum of indicators and reached an average of over 31 indicators per partner. The other half was more conservative in their selection process. The average number of indicators chosen among these partners was around 11 indicators per partner. It showed that some partners were more hesitant in choosing indicators than others.

This can be explained by:

1. a delayed progress of introducing VV-TOMM to their respective case study areas (e.g. if they had difficulties in mobilising the local stakeholders which were not part of the project from the beginning),

2. a general low availability of data and awareness for monitoring in their regions.

\subsection{Data collection}

Some case study areas were characterised by very active and strong tourism management and/or regional development organisations, such as the Trentino SPA in Italy and the Landkreis Forchheim in Germany. Others had no data on regional tourism development. Overall, the availability of data was the major hindering aspect to an immediate commitment to carry out TOMM for some partners when they were in contact with their local stakeholders. This confirms findings of Australian research. Moore et al. [13] consider the TOMM framework more difficult to apply than other frameworks, like ROS and LAC, because of its complexity. Brown et al. [11] also state that TOMM "needs large amounts of information und many resources for data management and manipulations". In contrast to the Australian example, which is a precisely defined island situation, the delimitation of the European study areas, and thus also the extent of data compilation, were not as clearly defined in all cases.

Only once 'creative data collection' approaches, as well as opportunities for obliging stakeholders (Federal County, tourism operators etc.) to provide data, were demonstrated, could the project partners be convinced to use the TOMM-model. To facilitate the process, the experts provided help and additional information on the indicator chart. After two VV-TOMM meetings, all partners agreed on the necessity to introduce indicators and to collect data or evaluate the performance of indicators already in use in their case study areas. Furthermore, they recognised the potential of VV-TOMM. It provided opportunities to work together with stakeholders and institutions to collect data, and it established long-term efficient monitoring systems.

\subsection{Long-term perspective}

Project partners went through an awareness raising process concerning the necessity of data collection and monitoring of tourism development processes in the long term. Before the start of the project, only few of them recognised the 
benefits of surveying tourism concepts and formulating management actions. The orientation of TOMM towards desired conditions without talking about limits helped to increase acceptance of the concept.

During the meetings, the benefits were compared to the additional costs. Best practice examples demonstrated the value of monitoring development processes, especially in areas with little or no tourism activity to that point. In this context, the application for support and funding by administrations and higher level tourism organisations were addressed in particular. The tourism regions realised the advantage of monitoring data to justify success, and the need to present a strategic concept with a long-term perspective.

\section{Discussion}

In the context of VV-TOMM, which referred to areas with beginning or barely developed tourism activities, this framework proved to be an excellent guide for establishing and improving tourism actions at first hand. Difficulties became visible later on in the process, which confirm criticism mentioned in previous studies.

For most of the VV-TOMM case study areas, the evaluation of common values and the definition of a strategic positioning, as provided in phase one, was essential, since they were at a starting phase of stronger tourism development and had to identify a new, appropriate niche market. Many of the project partners had not profoundly analysed their niche market and target groups before this project. During the selection process of desired conditions and indicators, tourism stakeholders faced international comparison and encountered good practice examples. VV-TOMM served as a 'catalyst' in raising questions and discussing visions and development options. For case study areas with existing tourism management structures, the second phase of TOMM was of special relevance. Only a minority of responsible stakeholders had recognised the need for broad, multi-dimensional monitoring of their performance before the project. Data compilation in several case study areas was limited by a lack of resources in terms of staff and budget. The inefficiency of tourism development without monitoring only became evident through the discussion process, especially for inexperienced, small tourism businesses and stakeholders. Furthermore, they learned of the existence of un-used data sources and additional inexpensive ways of collecting data. TOMM was a suitable framework in this context, since it strengthens dialogue with and between the stakeholders.

Problems, such as those mentioned before, are very typical for remote areas with little experience in tourism planning and management, and were exacerbated by the high demand for data and for effective response to indicators $[11,13]$. It became clear that, under these conditions, strong expert advice is needed to keep the process going. Within the transnational cooperation, only phase one and two of the TOMM process could be approached. With regard to the complexity of the monitoring system and the very low budget resources in some of the case study areas, the continuation of VV-TOMM is at risk. Changes of personal responsibilities and the lack of a coordinator in some areas after the 
project lifetime pose a particular challenge, since the effective implementation of management actions has been slow even in the original application on Kangaroo Island [1].

\section{Conclusion}

Findings of the international comparison demonstrate the potential of the TOMM-framework to encourage a learning process about successful and sustainable destination development, and about the need to monitor data of several dimensions in order to survey and adapt the tourism strategy if needed. In Eastern European partner regions, in particular, an awareness-raising process towards a coordinated and structured development of tourism was initiated, which helped tourism stakeholders at a local level to communicate the need for data compilation and monitoring procedures to the responsible higher levels (authorities/ politics).

On the other hand, the European application identified limitations regarding the idea of the implementation, which is primarily driven by local stakeholders. It became evident that at certain steps (e.g. selection of indicators, definition of desired conditions) expert knowledge is explicitly needed as support - in particular in remote areas with starting or re-establishing tourism initiatives.

\section{Acknowledgements}

We thank all our project partners for their collaboration in the research process of introducing VV-TOMM. Special thanks are due to our local partners in Burgenland, in particular the regional and national development/tourism authorities.

\section{References}

[1] Manidis Roberts Consultants, Developing a Tourism Optimisation Management Model (TOMM). Surrey Hills, N.S.W.: Manidis Roberts Consultants, 1997.

[2] Miller, G., Twining-Ward, L., Monitoring for a sustainable tourism transition. The Challenge of Developing and Using Indicators. CABI Publishing: Wallingford, UK, 2005.

[3] Newsome, D, Moore, S. and Dowling, R., Natural Area Tourism: Ecology, Impacts and Management, Second Edition. Channel View Publications, Buffalo, NY, 2013.

[4] Clark, R. \& Stankey, G., The Recreation Opportunity Spectrum: A Framework for Planning, Management, and Research. USDA Forest Service Genereal Technical Report, PNW-98, 1979.

[5] Graefe, A.R., Kuss, F.R., \& Vaske, J.J., Visitor impact management: The planning framework. National Parks and Conservation Association, Washington DC, 1990. 
[6] Stankey, G.H., Cole, D.N., Lucas, R.C., Petersen, M.E., Frissel, S.S., The limits of acceptable change (LAC) system for wilderness planning, USDA Forest Service, General Technical Report, INT-176, Ogden 1985.

[7] National Park Service, VERP: Visitor Experience and Resource Protection framework. US Department of Interior, National Park Service Denver, Service Center: Denver, 1997.

[8] Burns, R. C., Arnberger, A., von Ruschkowski, E., Social Carrying Capacity Challenges in Parks, Forests, and Protected Areas: An Examination of Transatlantic Methodologies and Practices. International Journal for Sociology, 40(3), pp. 30-50, 2010.

[9] Tourism Optimisation Management Model, KI TOMM Strategic Plan Kangaroo Island 2010-2013, 2010.

[10] Mac Kay, K., Developing Community Tourism in Uganda, The Tourism Optimization Management Model, Workshop Report On Community Tourism Development Framework in Uganda June 21st, 2007.

[11] Brown G., Koth B., Kreag G., Weber D., Managing Australia's protected areas, a review of visitor management models, frameworks and processes, Sustainable Tourism CRC: Gold Coast, Qld, 2006.

[12] Brown, G. and Weber, D., Using public participation GIS (PPGIS) on the Geoweb to monitor tourism development preferences. Journal of Sustainable Tourism, 1, pp. 1-20, 2012.

[13] Moore, S., Smith, A. J., Newsome, D.N., Environmental Performance Reporting for Natural Area Tourism: Contributions by Visitor Impact Management Frameworks and their indicators. Journal of Sustainable Tourism, 11/4, pp. 348-375, 2003.

[14] Twining-Ward, L., and Butler R., Implementing STD on a Small Island: Development and Use of Sustainable Tourism Development Indicators in Samoa, Journal of Sustainable Tourism, 10/5, 2002.

[15] Jiricka, A., Salak, B., Pröbstl, U., Arnberger, A., Eder, R.,WP3 - Research and Analysis Final Report part II VVTOMM-the Tourism Optimization Management Model for the needs of marginal areas Managing and steering sustainable tourism development processes, Integration report. European Commission (ERDF), Bruxelles, 2011.

[16] Choi H.C. and Sirakayab, E., Sustainability indicators for managing community tourism, Tourism Management 27, pp. 1274-1289, 2006.

[17] Manning, E.W., Clifford, G., Dougherty, D. and Ernst, M., What tourism managers need to know: a practical guide to the development and use of indicators of sustainable tourism. World Tourism Organization: Madrid, Spain, 1996. 